\title{
Lidocaine Versus Ketamine Pretreatment on Propofol Injection Pain
}

\author{
Amir Murad Khudadad Boujan \\ Surgical department \\ College of Medicine \\ University of Sulaimani \\ Sulaimani, Iraq \\ amir.boujan@univsul.edu.iq
}

\section{Amanj A. Marouf}

Surgical department

College of Medicine

University of Sulaimani

Sulaimani, Iraq

marouf.amanj@gmail.com

\author{
Nashmeel fazeel Kareem \\ Anesthesia department \\ Sulaimani Teaching Hospital \\ Sulaimani, Iraq \\ nashmeelfazeel@yahoo.com
}

\author{
Salah Qadir Mahmood \\ Radiation department \\ Sulaimani Technical Institute \\ Sulaimani Polytechnic University \\ Sulaimani, Iraq \\ salahdeanoffice@hotmail.com
}

Volume 4 - Special Issue:

3rd International

Conference on Health \&

Medical Sciences: Insight

into Advanced Medical

Research (ICHMS 2019)

DOI:

10.24017/science.2019.

ICHMS.25

Received:

03 June 2019

Accepted:

2 July 2019

\section{Abstract}

Propofol is commonly used intravenous anesthesia induction drug but it causes ache upon use, many method with different results, have been suggested to prevent this pain, the current research was concluded in order to investigate the impact of lidocaine, ketamine in reducing the ache on giving intravenous propofol. This study is randomized controlled clinical trial lasting from June 2015 to November 2015 during which 107 consenting (ASA1 and ASA2) patients were prepared for elective operation with general anesthesia. They randomly split to three subgroups, A cannula (size20) used in the dorsum hand veins, standard monitor was established patients received either $2 \mathrm{~mL}(40 \mathrm{mg})$ of lidocaine or $2 \mathrm{~mL}$ (20mg) of ketamine and $2 \mathrm{~mL}$ of saline 1 min before injection 2.5 milligram per kilogram propofol. ache severity observed by using four number pain scale, zero $=$ none, one $=$ mild pain, two = moderate pain, and three = intense pain. Atracurium used for indotracheal intubation, isoflurane and fentanyl for anesthesia maintenance. There were no variations between the study groups regarding ASA status, Sex, age. The incidence of ache when injecting propofol were observed in the normal saline group was $86.5 \%$ and it was more than ketamine group 0\% and lidocaine group $20 \%$ 


\begin{abstract}
$(p=0.0002)$. In the normal saline pretreatment group $8.1 \%$ of the patient experienced severe pain, compared with $0 \%$ in the lidocaine and ketamine. It can be concluded that intravenous ketamine and lidocaine were equally effective in preventing Ache during propofol injection.
\end{abstract}

Keywords: propofol, pain, lidocaine, Ketamine.

\title{
1. INTRODUCTION
}

Propofol is the most frequently used intravenous anesthetic agent for anesthesia induction and maintenance, providing a smoother induction and quicker recovery compared to all other drugs such as thiopental [1]. Propofol consist of a phenol ring substituted with two isopropyl. It is not soluble in water,groups. includes $1 \%$ propofol, $5 \%$ soybean oil, and $0.6 \%$ egg lecithin. Propofol is nearly isotonic, non-hyperosmolar and has a $\mathrm{pH}$ of 6 to 8.5. So, pain on propofol injection is due to contact of propofol to the endothelial wall of vein and may cause irritation of adventitia and mediators release such as kininogen from kinin cascade. Propofol induction of general anesthesia may involve facilitation of inhibitory neurotransmission mediated by gamma aminobutyric acid (GABAA) receptor binding. This receptor is coupled to a chloride channel, and activation of the receptor lead to hyperpolarization of the nerve membrane [2].

Propofol on injection often causes mild to serious pain or discomfort [1], the occurrence of pain differs with regards to ages, which may be due to lower veins in children, more in children and teenagers. But in term of gender, the occurrence of propofol injection pain does not differ [3]. Propofol induce pain because contain phenol that can irritate the skin, mucous membrane. Another cause of pain due to, osmolality differences, and $\mathrm{PH}$ and the activation pain mediators [1]. Pain is believed to be caused by direct stimulation of venous nociceptive receptors after injection of propofol, the nerve impulse being transferred by myelinated A delta fibers [4]. The quality of pain has been defined as highly sharp, painful, or burning. Propofol injection pain after $10-20 \mathrm{~s}$ is immediately delayed. The instant pain is caused by irritation of the vein endothelium, while the delayed pain is caused by the release of mediators from the kinine cascade [1].

The propofol lipid solvent activates the kallikrein kinin plasma system that generates bradykinin that changes the local vein injected. This peripheral vein alteration can improve the contact between the aqueous phase propofol and the free nerve endings of the vessel, leading to propofol aggravation, caused pain [5].

There appear to be many variables affecting the incidence of pain on propofol injection. These include the site of injection, vein size, velocity of injection, aqueous propofol concentration and the buffering impact of blood and concomitant use drug such as local anesthetics [6].

Propofol pain can be decreased or avoided by injection into a big vein, changing the speed of injection, propofol solution mixed with 5\% dextrose, normal saline injection before propofol or intravenous injection of lidocaine with or without tourniquet, ketamine, Pethidine, metoclopramide and dexamethasone $[1,5,6]$.

Lidocaine is a short acting local anesthetic and antiarrhythmic agent widely used by injection and for surface application, the duration of action increase by adding vasoconstrictor [7]. For every form of local anesthetic operation, lidocaine has been used safely and efficiently, it has no uncommon function and is also a normal antiarrhythmic. Lidocaine used for percutaneo us infiltration in concentrations of 0.5-1.0 percent but for peripheral nerve blocks of 1.5 percent.

Lidocaine 5\% was used for anesthesia with subarachnoids, although the degree of spread is un predictable and has a brief length of action. With a concentration of 1-2\%, lidocaine generates 
short-term epidural anesthesia. Lidocaine is also accessible as a $4 \%-10 \%$ spray, $5 \%$ cream, $5 \%$ medicated plaster for topical use [8].

Intravenous Lidocaine pretreatment has been used to reduce propofol injection pain; lidocaine has analgesic impact due to a local anesthetic effect, and inhibits the enzyme cascade leading

to kininine release. Lidocaine has relaxed the vascular smooth muscle

Different concentrations of lidocaine were used as a pretreatment of $2 \mathrm{ml}$ of $2 \%(40 \mathrm{mg}), 4 \mathrm{ml}$ of $1 \%(40 \mathrm{mg})$ or $1 \mathrm{ml}$ of either $1 \%(10 \mathrm{mg})$ or $2 \%(20 \mathrm{mg})$ of lidocaine mixed with $19 \mathrm{ml}$ of $\mathrm{p}$ er

ropofol. Ketamine is a phencyclidine derivative that results in analgesic modulation at the neu raxial stage via NMDA and $\mu$-opiate receptors [8].

Ketamine has powerful analgesic and anesthetic characteristics at the local level.

The decrease in propofol injection pain seems likely to have been the consequence of a periph eral action that attenuated the afferent pathways of pain. These receptors may be activated by ketamine as an NMDA receptor antagonist either in the vascular endothelium or in the central nervous system [8]. Ketamine's most significant pharmacological characteristics are its noncompetitive N-methyl-D-aspartate (NMDA) receptor antagonist and its analgesic action at sub-

anaesthetic dose isthought to be mainly due to antagonism in the brain and spinal cord with th e NMDA receptor. [7]. Ketamine may be given by multiple rote of administration including intravenous, oral, subcutaneous, intranasal, transdermal [10].

Table1: Font and Format setting

\begin{tabular}{ll}
\hline Title & Measurements \\
\hline Article Title & $24 \mathrm{pt}$, Bold \\
\hline Author name & $9 \mathrm{pt}$, bold \\
\hline Author affiliation & $8 \mathrm{pt}$ \\
\hline Abstract & $10 \mathrm{pt}$, italic, bold \\
\hline Keywords & $10 \mathrm{pt}$, \\
\hline Heading $\mathbf{1}$ & $10 \mathrm{pt}$, Capital letters, Center, Bold \\
\hline Heading 2 & $10 \mathrm{pt}$, Bold, Left, Italic \\
\hline Paragraph & $10 \mathrm{pt}$ \\
\hline Figure captions & $9 \mathrm{pt}$, Center, after the picture \\
\hline Table captions & $9 \mathrm{pt}$, Center, before the table \\
\hline Table / cell Margin & 0.03 \\
\hline
\end{tabular}

\section{METHODS AND MATERIALS}

This is a normal saline-controlled randomized study that conducted at the anesthesia department in Sulaimani Teaching Hospital on patients undergoing general anesthesia for elective general surgery, between May 2015 and November 2015 after gaining local ethical committee acceptance.

107 consented patients with age range from twenty to sixty years old and ASA classification 1 and 2, patients randomly divided into three groups;

- $\quad \mathrm{N}$ : 37 patients took $2 \mathrm{ml} 0.9 \%$ sodium chloride

- $\quad$ L: 35 patients took $2 \mathrm{ml}(40 \mathrm{mg})$ of Lidocaine

- $\mathrm{K}: 35$ patients took $2 \mathrm{ml}$ (20mg) ketamine 
Exclusion criteria were patient with severe respiratory, cardiovascular, cardiac conduction defect, neurological or renal disease (ASA III, IV), patient with difficulty in communication, hemodynamically unstable patient, mallampati class (III, IV), patient had allergy to the study medications, analgesic drug or any sedative consumption in the preoperative period and Patient with difficult cannulation.

All patients were managed with an intravenous cannula (size 20) inserted on the dorsum of the patient hand, standard monitoring like electrocardiogram, temperature, blood pressure (noninvasive), and pulse oximeter was established. Research drug was given 1minute from giving propofol (2.5mg/kilogram), the propofol injected over15 seconds, the ache level was evaluated and recorded, using four number rate scale, a score zero to three represents None (0), mild pain (1), moderate pain (2) and sever pain (3). Patients were questioned about the pain presence on injecting propofol their answers, facial responses, tears, hand withdrawal and all that recorded.

- If it was negative answer to the questions equal to none.

- If patient answered yes to pain on question and there were no other signs (behavioral) this equal to mild.

- If patient report pain spontaneously without asking or had behavioral signs this equal to moderate.

- If patient had strong vocal answer or his answer associated with grimacing of the face, tears or arm withdrawing this equal to sever

Tracheal intubation was facilitated with injection of atracurium (non- depolarizing neuromuscular blocking agent); fentanyl and isoflurane were used for maintenance. Anesthesia was maintained as per surgical requirement.

Statistical Package for the Social Sciences version 22.0 where used to analyze the Data, Also, Analysis of variance test, $\mathrm{T}$ students test was used on the demographic data. Statistical significance set at $\mathrm{p}<0.05$.

\section{RESULTS}

107 patients involve in this research, in comparing patients age, sex and ASA physical status we found no significant differences between study groups (Table 1).

Table1: Comparison between Ages, gender and ASA physical status in study groups.

\begin{tabular}{|l|c|c|c|c|}
\hline variable & $\begin{array}{c}\text { ketamine } \\
(\mathrm{N}=35)\end{array}$ & $\begin{array}{c}\text { lidocaine } \\
(\mathrm{N}=35)\end{array}$ & $\begin{array}{c}\text { Normal saline } \\
(\mathrm{N}=37)\end{array}$ & P value \\
\hline $\begin{array}{l}\text { Age(year) } \\
\text { Mean } \pm \text { SD }\end{array}$ & $35.46 \pm 11.92$ & $40.03 \pm 10.84$ & $39.97 \pm 9.66$ & 0.1 \\
\hline $\begin{array}{l}\text { Gender } \\
(\mathrm{M}: \mathrm{F})\end{array}$ & $4 / 31$ & $8 / 27$ & $7 / 30$ & 0.4 \\
\hline ASA (I:II) & $31 / 4$ & $21 / 14$ & $24 / 13$ & 0.084 \\
\hline
\end{tabular}


While comparing the lidocaine group to the normal saline group, we found that there was significant difference between the two groups and the overall patients number having pain (mild, moderate, sever) was significantly less in lidocaine group. (Table 2, Figure 1)

Table2: Comparison of pain score, regarding of lidocaine and normal saline

\begin{tabular}{|c|c|c|c|}
\hline Pain Score & $\begin{array}{c}\text { Lidocaine } \\
\text { N }(\%)\end{array}$ & $\begin{array}{c}\text { Normal saline } \\
\text { N }(\%)\end{array}$ & p-value \\
\hline no pain & $28(80 \%)$ & $5(13.5 \%)$ & 0.003 \\
\hline Mild & $6(17.1 \%)$ & $19(51.4 \%)$ & 0.013 \\
\hline Moderate & $1(2.9 \%)$ & $10(27.0 \%)$ & 0.009 \\
\hline sever & $0(0 \%)$ & $3(8.1 \%)$ & 0.092 \\
\hline No pain: Pain & $28 / 7$ & $5 / 32$ & 0.0002 \\
\hline
\end{tabular}

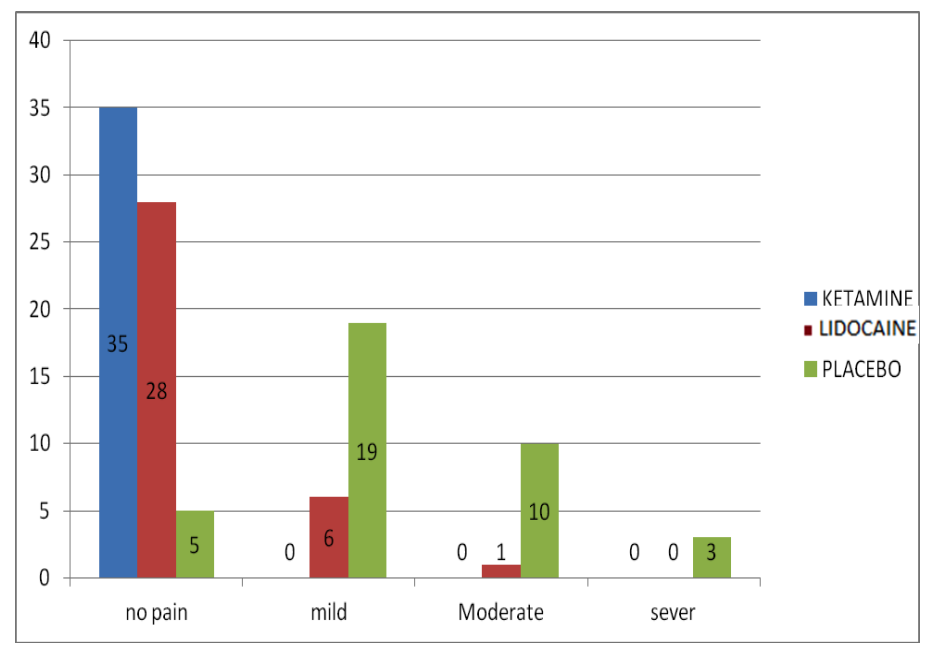

Figure1: shows differences in pain score between study groups.

In comparing the ketamine group to the normal saline group, we found that there were differences between those groups and it was statically significant and the overall patients number having pain (mild, moderate, sever) was significantly less in ketamine group. (Table 3, Figure 1) 
Table3: Comparison of pain score, regarding of ketamine and normal saline.

\begin{tabular}{|c|c|c|c|}
\hline \multirow{2}{*}{ Pain Score } & $\begin{array}{c}\text { Ketamine } \\
\mathrm{N}(\%)\end{array}$ & $\begin{array}{c}\text { Normal saline } \\
\mathrm{N}(\%)\end{array}$ & p-value \\
\hline no pain & $35(100 \%)$ & $5(13.5 \%)$ & 0.009 \\
\hline mild & $0(0 \%)$ & $19(51.4 \%)$ & 0.002 \\
\hline Moderate & $0(0 \%)$ & $10(27.0 \%)$ & 0.002 \\
\hline sever & $0(0 \%)$ & $3(8.1 \%)$ & 0.092 \\
\hline No pain: Pain & $35 / 0$ & $5 / 32$ & 0.0002 \\
\hline
\end{tabular}

When comparing the ketamine group to the lidocaine group, we found that there were differences between the groups and those differences were significant in mild ache but in overall number of patients having pain to no pain was significantly less in ketamine group. (Table 4, Figure 1)

Table4: Comparison of pain score, regarding of ketamine and lidocaine.

\begin{tabular}{|c|c|c|c|}
\hline Pain Score & $\begin{array}{c}\text { Ketamine } \\
\mathrm{N}(\%)\end{array}$ & $\begin{array}{c}\text { Lidocaine } \\
\mathrm{N}(\%)\end{array}$ & p-value \\
\hline no pain & $35(100 \%)$ & $28(80 \%)$ & 0.4 \\
\hline mild & $0(0 \%)$ & $6(17.1 \%)$ & 0.01 \\
\hline Moderate & $0(0 \%)$ & $1(2.9 \%)$ & 0.31 \\
\hline sever & $0(0 \%)$ & $0(0 \%)$ & None \\
\hline No pain: Pain & $35 / 0$ & $28 / 7$ & 0.006 \\
\hline
\end{tabular}

\section{DISCUSSION}

This use of propofol as intravenous anaesthetic due to the high quality of anesthesia and fast recovery agent has risen quickly [9]. The injection pain caused by Propofol is linked to the quantity of free propofol in the aqueous stage. The free propofol contact with free nerve ending 
of vessels activates the plasma kinin-kallikrein system, which release pain mediators locally. Pain caused by propofol injection can be immediate or delayed; instant pain is probable due to direct irritant impact whereas delayed pain is probable due to indirect impact through the kinine cascade [11].

It is extremely desirable to avoid pain with propofol injection; many techniques have been use $\mathrm{d}$ to decrease the incidence of pain with variable outcomes on propofol injection [1].

Our randomized, focused on showing the efficacy of different medicines. Lidocaine and ketam ine pretreatments were contrasted with placebo organizations to reduce the incidence and seve rity of propofol pain. Propofol injection without any medicine (placebo group) suffered pain in most of patients, some of them complaining of strong pain. But the impact of pain via pretreatment with lidocaine and ketamine decreases and no patient is having severe pain with ketamine and lidocaine. Thus, both ketamine and lidocaine pretreatment decreased incidence of pain on propofol injection and this was statistically significant. But Incidence of pain significantly less in ketamine group. This agree with the following studies

Saadawi Ertok et al, after they conducted a study on 125 patients for evaluation of efficacy ketamine, lidocaine, meperidine, thiopental compared to placebo to minimize propofol injection pain. They reported that the incidence of pain in all treatment groups was considerably smaller than in placebo. However, pretreatment with ketamine was found to be the most efficient in attenuating propofol-related pain [12].

This agrees with Zahedi $\mathrm{H}$ et al, studied 500 patients compared ketamine, lidocaine to placebo groups in the Preventing propofol pain injection they recorded considerably reduced pain incidence and intensity in all study groups than the treatment group. And ketamine 100 microgram $/ \mathrm{kg}$ group had the incidence of pain is considerably smaller relative to lidocaine group injection pain [10].

Seung -WooKoo, sun jun cho et al, studied 240 patients and compared lidocaine, ketamine 3 different dose to placebo group, the results showed that a dose of ketamine $100 \mathrm{mcg} / \mathrm{kg}$ the incidence of propofol induced pain relative to lidocaine and placebo can be reduced [13].

Bano F, Zafar S et al, studied 100 patients. They received $0.5 \mathrm{mg} / \mathrm{kg}$ ketamine in volume $2 \mathrm{ml}$ and $2 \mathrm{ml}$ of lidocaine, the incidence of propofol pain in the ketamine group was smaller but remained statistically small and this differs from our study because they injected $25 \%$ of the calculated propofol dose with in 15 second and performed measurement while we injected the whole dose then performed measurement [14].

While Polat R, Aktay M, et al, studied 250 patients receiving remifentanil, lidocaine, ketamine, metoclopramide compared to placebo lidocaine or metoclopramide pretreatment decreased the incidence and severity of propofol caused pain fairly and substantially compared to pretreatment with ketamine and remifentanil. Although they agree with our study that lidocaine significantly reduces pain compared to placebo but disagree with our study in that ketamine is better than lidocaine probably because we used a higher dose of ketamine than this study [11].

Vida Ayatollahin et al, studied 140 patients receiving ephedrine, ketamine, lidocaine compared to placebo, they found that ketamine has the best results between the drugs but it was not statistically significant this because they used a lower dose than the dose we used [15].

Leena Jalota, Vicki Kalira, et al analyzed from 177 randomized controlled trials totaling 25260 adults. The general risk of propofol injection pain alone was approximately $60 \%$. Statistically, they calculated that the two most effective procedures to decrease pain in the injection of propofol were the use of the antecubital vein or pretreatment with lidocaine in combination with venous occlusion when the hand vein was selected on the premise of autonomous efficacy [16].

In our study dose of lidocaine was $(40 \mathrm{mg}$ ) and most of the Patients had no propofol injection pain that was statistically important in comparison with placebo organizations. Because lidocaine has a local anesthetic impact or an inhibitory impact on the enzyme cascade that result in kinin release [4]. The result of the following studies supported the findings of our study. 
Shreyasi Ray et al, studied 63 patients, compared efficacies of lidocaine $40 \mathrm{mg}$ with fentanyl pretreatment to reduce propofol injection pain, the result shown that lidocaine and fentanyl effectively reduce propofol injection pain compared to ordinary placebo saline [5].

Nathanson, Michael $\mathrm{H}$ et al, compared alfentanil $1 \mathrm{mg}$, lidocaine $40 \mathrm{mg}$ to placebo group to reduce pain during propofol injection; the result showed that both lidocaine and alfentanil the incidence of pain was considerably smaller than the placebo group [17].

Pang WW, wang PY et al, researched 105 patients randomly assigned to receive tramadol, lid ocaine $60 \mathrm{mg}$ or normal saline as a pretreatment for pain reduction with propofol injection.

The results showed that both tramadol and lidocaine considerably decreased the incidence and intensity of propofol injection pain relative to normal saline [18]. Although this study results agree with our study but still they used a much higher dose of lidocaine than our dose.

King Sharon Y et al, they studied 368 females, were allocated to one of four groups to received propofol mixed with different dose of lidocaine $(5 \mathrm{mg}, 10 \mathrm{mg}, 20 \mathrm{mg})$ compared to placebo, the result was shown that lidocaine $20 \mathrm{mg}$ Reduces the incidence and severity of pain in propofol injection considerably. They got significant decrease in pain with $20 \mathrm{mg}$ lidocaine on propofol injection is much less than the lidocaine dose that we used, and this discrepancy may be because they mixed propofol with lidocaine and their research done only on female gender [19].

Ali pour $\mathrm{M}$ et al, studied 336 patients compared many drugs and lidocaine to placebo on reducing the pain of propofol injection, the result showed that lidocaine is more significantly reduces pain on propofol injection than the other groups [20]. MGupto, S Mishro et al, studied a 100 female patients for evaluation lidocaine, pethidine, dexamethasone compared to placebo group results to decrease the incidence of propofol pain showed that all pretreatment groups the incidence of propofol injection pain reduces considerably more than placebo [9]. Although this study result agrees with our study but still it was used a much lower dose of lidocaine than our dose, this difference may be related to gender (only female) and the patient received diazepam $5 \mathrm{mg}$ on night before surgery.

Similarly, ketamine $(20 \mathrm{mg})$ pretreatment decreased the incidence of propofol injection pain and no anyone of patient felt pain, the distinction between ketamine and placebo group was statistically important. Ketamine acts on a variety of receptors

in the central nervous system and vascular endothelium, it is a non-competitive N-methyl-

$\mathrm{D}$ aspartic acid receptor antagonist and opioid ì receptor agonist [11]. The following studies supports our results such as $\mathrm{N}$ kad, P Malik et al, studied 100 patients compared ketamine to placebo group reducing the incidence of pain in propofol injection with intravenous ketamine is an easy and secure way to decrease the incidence of pain in propofol injection [21]. Suzuki S et al, studied 43 patients, compared ketamine to placebo group for Prevention of pain injection with propofol. Ketamine pretreatment the incidence and severity of pain associated with propofol injection decreased considerably before propofol administration [22]. C.H. Tan, M. K. onsiong et al, studied 100 female patients and compared intravenous Ketamine (10 mg) $1 \mathrm{ml}$ to normal saline $1 \mathrm{ml}$ pretreatment for propofol injection pain showed that $84 \%$ of the saline control patient had mild or severe discomfort compared to $26 \%$ of those who had pretreatment with ketamine. This difference from our study may be due to the higher dose of ketamine we used so that $0 \%$ had pain on propofol injection [23]. Hong SW, et al, studied on 225 patients, the patient received $2 \mathrm{ml}$ of normal saline, $2 \mathrm{ml}$ of ketamine $20 \mathrm{mg}, 2 \mathrm{ml}$ of remifentanil at different dose the results showed that groups of ketamine experienced Much less frequent and intense pain than normal saline groups [24].

\section{CONCLUSION}

Pretreatment with either ketamine or lidocaine is an effective method for propofol pain prevention and Ketamine is superior on lidocaine. Further study on other drugs that may prevent pain during propofol injection. 


\section{REFERENCE}

[1] D. Singh, S. Jagannath, S.Priye "Prevention of propofol injection pain: Comparison between lidocaine and ramosetron" Journal of Anaesthesiology and Clinical Pharmacol, 30 (2) pp. 213-216, 2014.

[2] J. Butterworth. David Mackey. John Wasnick. Morgan and Mikhails Clinical Anesthesiology, McGraw-Hill Education, 2013.

[3] C. H. Tan and M. K. Onsiong. "Pain on injection of propofol" journal of Anaesthesia, 53(5) pp.468-476, 1998.

[4] E. Liljeroth, Pain induced by propofol, Lund university medical faculty, doctoral dissertation series, 2007.

[5] S Ray, R Pal, S Pal, J Kirtania, D Sarbapalli, "Preclusion of pain on injection with propofol: Evaluating the effects of lignocaine or fentanyl pretreatment" Anesth Essays Res 5 pp.33-38, 2011.

[6] M Nakane , H Iwama. "Potential mechanism of propofol-induced pain on injection based on studies using nafamostat mesilate" British journal of anesthesia, 38(3) pp. 397-404, 1999.

[7] T.N. Calvey and N.E. Williams, Principles and practice of pharmacology for anesthetists, Wiley on line library, 2008.

[8] A. R. Aitkenhead, G. David, J. Rowbotham, text book of anesthesia, Churchill Livingstone, Elsevier, 2007.

[9] M Gupta, S Mishra, D Gupta, M Gujjar, "Prevention of Pain on Propofol Injection: A Comparative, Randomized, Double Blind Study between Lignocaine, Pethidine, Dexamethasone and Placebo" The Internet Journal of Anesthesiology, 11 (2) 2006.

[10] H. Zahedi, M. Nikooseresht. "Prevention of propofol injection pain with small dose ketamine" M.E.J.ANESTH, 20 (3) pp.401-404, 2009.

[11] R. Polat, M. Aktay, O. Özlü. "The effects of remifentanil, lidocaine, metoclopramide, or ketamine pretreatment on propofol injection pain" M.E.J. ANESTH, 21 (5) pp. 673-677, 2012.

[12] I Saadawy, E Ertok, A Boker. "Painless injection of propofol: pretreatment with ketamine vs thiopental, meperidine, and lidocaine" Middle East J Anesthesiol, 19 (3) pp.631-44, 2007.

[13] S. Koo, S. Cho, Y. Kim, "Small-Dose Ketamine Reduces the Pain of Propofol Injection"Anesth Analg, 103 pp.1444-1447, 2006.

[14] F Bano, S Zafar, S Sabbar, S Aftab , S. Haider. ".Intravenous ketamine attenuates injection pain and arterial pressure changes during the induction of anesthesia with propofol: a comparison with lidocaine" Journal of the College of Physicians and Surgeons--Pakistan , 17(7) pp.390-393, 2007

[15] V. Ayatollahi, S. Behdad, S. Kargar, "Comparison of Effects of Ephedrine, Lidocaine and Ketamine with Placebo on Injection Pain, Hypotension and Bradycardia Due to Propofol Injection: A Randomized Placebo Controlled Clinical Trial " Acta Medica Iranica, 50(9) pp.609-614, 2012

[16] L. Jalota, V. Kalira, E. George. "Prevention of pain on injection of propofol: systematic review and meta-analysis" BMJ, pp.342, 2011.

[17] MH Nathanson, NM Gajraj, JA Russell. "Prevention of pain on injection of propofol: A comparison of lidocaine with alfentanil" Anesth Analg, 82 pp.469-71, 1996.

[18] WW Pang, PY Huang, DP Chang, MH Huang. "The peripheral analgesic effect of Tramadol in reducing propofol injection pain: a comparison with lidocaine" Reg Anesth Pain Med, 24 (3) pp.246-9, 1999.

[19] SY King, FM Davis, JE Wells, DJ Murchinson, PJ Pryor. "Lidocaine for the prevention of pain due to injection of propofol" Anesthesia and Analgesia, 74(2) pp. 246-249, 1992.

[20] M. Alipour, Masoomeh Tabari, and Masoomeh Alipour "Paracetamol, Ondasteron, Granisetron, Magnesium Sulfate and Lidocaine and Reduced Propofol Injection Pain" Iran Red Crescent Med, 16(3) 2014

[21] N Kad, P Malik, J Dureja, A Thakur. "Ketamine pretreatment to alleviate the pain of propofol injection" The Internet Journal of Anesthesiology, 20 (2) pp.1-5, 2008.

[22] S Suzuki, T Masamune, A Nonaka. " Pretreatment with ketamine reduces incidence and severity of pain on propofol injection" Masui, 51(2) pp.140-143, 2002.

[23] CH Tan, MK Onsiong, SW Kua. "The effect of ketamine pretreatment on propofol injection pain in 100 women" Anesthesia, 53(3) pp.302-305, 1998.

[24] SW Hong, KH Kwak. "The Effects of Different Doses of Remifentanil on Propofol Injection Pain: A Placebo Controlled Comparison of Ketamine" Korean J Anesthesiol, 51(3) pp.302-307, 2006. 